женерная графика», Саратовский государственный аграрный университет имени Н.И. Вавилова. Россия.

Перетятько Андрей Владимирович, канд. техн. наук, доиент кафедры «Математика, механика и инженерная графика», Саратовский государственный аграрный университет имени Н.И. Вавилова. Россия.
410056, г. Саратов, ул. Советская, 60.

Тел.: (8452) 74-96-63.

Ключевъе слова: вентилятор; пневматический встряхиватель; давление; воздушный поток; гидравлическое сопротивление.

\title{
AXIAL FAN SELECTION FOR PNEUMATIC FRUIT SHAKER
}

Eliseev Mikhail Semenovih, Doctor of Technical Sciences, Professor of the chair "Mathematics, Mechanics and Engineering Graphics", Saratov State Agrarian University named after N.I. Vavilov. Russia.

Vasylchikov Valentin Vladimirovich, Candidate of Technical Sciences, Associate Professor of the chair "Mathematics, Mechanics and Engineering Graphics”, Saratov State Agrarian University named after N.I. Vavilov. Russia.

Leontyev Aleksey Alekseevich, Candidate of Technical Sciences, Associate Professor of the chair "Mathematics, Mechanics and Engineering Graphics", Saratov State Agrarian University named after N.I. Vavilov. Russia.

Maradudin Aleksey Maksimovich, Candidate of Technical Sciences, Associate Professor of the chair "Mathematics, Mechanics and Engineering Graphics", Saratov State Agrarian Uni- versity named after N.I. Vavilov. Russia.

Peretyatko Andrey Vladimorovich, Candidate of Technical Sciences, Associate Professor of the chair "Mathematics, Mechanics and Engineering Graphics", Saratov State Agrarian University named after N.I. Vavilov. Russia.

Keywords: fan; pneumatic shaker; pressure; airflow; hydraulic resistance.

The article describes a method for an axial fan selection for a pneumatic fruit shaker. Based on the design of the pneumatic shaker and the input parameters of its operation (air flow rate at the nozzle exit and the crown size of the treated trees), the fan characteristics (capacity, generated pressure, and power consumption) are determined. The brand of suitable commercially available fan is recommended.

\section{КРУПИН Александр Евгеньевич, Нижегородский государственный инженерно-экономический университет}

В статъе представлен алгоритм по обоснованию целесообразности упрочнения зубъев борон наплавкой и результаты его реализации. В частности, руководствуясъ существующими методиками, предлагается определить стоимость материалов, заработную плату рабочего, проводящего наплавку, затраты электроэнергии на наплавку, а также накладные расходы в расчете на один зуб бороны, упрочненный предлагаемым способом. Определено количество наплавленных зубъев борон и зубъев без упрочнения, которые потребуют замены при переходе в предельное состояние. Опираясъ на полученные результаты выявлена экономия затрат на покупку зубъев, требующих замены, в течение года на одну борону и в иелом по предприятию.

Введение. Растущая потребность в инновациях и повышение спроса на них должны обеспечить преодоление разрыва между наукой и производством [1, с. 110]. Известно, что для обеспечения разработки, производства и освоения каких-либо нововведений обязательно требуются денежные вложения [2, с. 132]. Их количество должно быть оправдано и четко согласовано с получаемой при этом экономией. Тем самым должны учитываться требуемые капиталовложения и срок их окупаемости. В нашем случае затраты будут связаны с мероприятиями, направленными на повышение долговечности зубьев борон. Зубья борон отечественного производства зачас-

тую имеют более низкую долговечность по сравнению с аналогами зарубежного производства, что предопределяет разработку различных способов повышения ресурса этих деталей. К тому же в условиях импортозамещения обеспечение эффективности работы становится особенно актуальным [5, с. 96].

Известно, что малоценные и быстроизнашивающиеся детали, применяемые в конструкции сельскохозяйственных машин, могут оказывать негативное влияние на такие показатели надежности, как ресурс, срок службы, коэффициент технической готовности техники и др. К деталям такого плана следует отнести и рабочие органы зубовых борон. Ранее нами было предложено упрочнение их ручной наплавкой [4]. На основании существующих рекомендаций $[3,7,8]$ были выявлены факторы, оказывающие наибольшее влияние на износостойкость зубьев и определены их оптимальные значения. Следующим этапом является определение экономической эффективности применения предлагаемого способа упрочнения зубьев борон. 
Цель исследования - технико-экономическое обоснование целесообразности ручной электродуговой наплавки зубьев борон.

Методика исследований. Технико-экономическая оценка ручной наплавки осуществляется для зубьев борон с учетом затрат на используемые материалы, электроэнергию, оплату труда рабочих и накладные расходы. Все необходимые расчеты проводятся с учетом известных методик и рекомендаций [6].

Результаты исследований. Себестоимость ручной наплавки одного рабочего органа в условиях ОАО «Плодопитомник» Лысковского района Нижегородской области будет определяться по формуле:

$$
\mathrm{C}_{1}=\mathrm{C}_{\mathrm{M} 1}+\mathrm{C}_{31}+\mathrm{C}_{\ni 1}+\mathrm{C}_{\mathrm{HP} 1}, 10 \text { руб. }
$$

где $C_{\mathrm{M}}$ - стоимость материалов, расходуемых на один зуб бороны, руб.; $C_{31}$ - заработная плата рабочего, проводимого наплавку одного зуба бороны, руб.; $C_{\ni 1}$ - затраты электроэнергии на наплавку одного зуба бороны, руб.; $C_{\mathrm{HP1}}-$ накладные расходы (по данным ОАО «Плодопитомник» $100 \%$ от $C_{31}$ ), руб.

Стоимость материалов, расходуемых на наплавку зуба бороны, определим следующим образом:

$$
\mathrm{C}_{\mathrm{M} 1}=\mathrm{P}_{\mathrm{A} 1} \mathrm{C}_{\mathrm{A}} \text {, руб., }
$$

где $\mathrm{C}_{\mathrm{A}}$ - стоимость электрода, руб./кг $\left(\mathrm{C}_{\mathrm{A}}=\right.$ $=220$ руб./кг) [9]; $\mathrm{P}_{\mathrm{A} 1}$ - расход электрода при наплавке одного зуба, кг.

Расход электродов на 1 кг наплавленного материала составляет в среднем 1,4 кг. Масса детали после наплавки при оптимальных режимах увеличивается в среднем на 0,027 кг. Таким образом, на один зуб расход электрода составит 0,038 кг $(1,4 \cdot 0,027)$.

Тогда стоимость расходуемого материала электрода при упрочнении одного зуба бороны составит:

$$
\mathrm{C}_{\mathrm{M} 1}=0,038 \cdot 220=8,4 \text { руб. }
$$

Затраты на оплату труда рабочего, выполняющего электродуговую наплавку одного зуба бороны, вычисляется по следующей формуле:

$$
\mathrm{C}_{31}=\mathrm{T}_{\text {оп }} \mathrm{C}_{\mathrm{\Psi C}} \mathrm{K}_{\Pi 3} \text {, руб. }
$$

где $\mathrm{T}_{\text {оп }}$ - основное время упрочнения одного зуба, ч; $\mathrm{C}_{\text {чс }}$ - часовая тарифная ставка работника, по данным предприятия, равна 100 руб./ч; $К_{\text {пз }}$ повышающий коэффициент заработной платы, $\mathrm{K}_{п з}=1,025-1,030$.

Основное время ручной наплавки определяется по формуле:

$$
\mathrm{T}_{\text {оп }}=0,038 / 1,0=0,04 \text {, }
$$

где $t$ - производительность наплавки, кг/ч (1,4 кг/ч для электрода диаметром 4 мм [10]). С учетом сложности конфигурации детали примем1 кг/ч.

Таким образом, время получения наплавляемого слоя для одного зуба бороны составит:

$$
\mathrm{T}_{\text {оп }}=0,038 / 1,0=0,04 \text { ч. }
$$

Заработная плата за наплавку одного зуба бороны составит:

$$
\mathrm{C}_{31}=0,04 \cdot 100 \cdot 1,025=4,1 \text { руб. }
$$

Затраты на электроэнергию при упрочнении одного зуба бороны определяются по формуле

$$
\mathrm{C}_{\text {э1 }}=\mathrm{C}_{\text {ип1 }}+\mathrm{C}_{\text {о1}} \text {, руб., }
$$

где $\mathrm{C}_{\text {ип1 }}$ - затраты на электроэнергию потребляемую источником электроэнергии при наплавке одного зуба бороны, руб.; $C_{01}$ - затраты электроэнергии на освещение участка при наплавке одного зуба бороны, руб.

Определение затрат на электроэнергию, потребляемую источником тока при наплавке одного зуба бороны, осуществляется по формуле:

$$
\mathrm{C}_{\text {ип1 }}=\mathrm{P}_{\text {ип1 }} \mathrm{C}_{\text {кв }} \text {, руб. }
$$

где $\mathrm{C}_{\text {кв }}$ - стоимость 1 кВт электроэнергии, руб., (по данным ОАО «Плодопитомник», $\mathrm{C}_{\text {кв }}$ равна 6,45 руб.); $\mathrm{P}_{\text {ип1 }}$ - расход электроэнергии на работу источника электрического тока для упрочнения одного зуба бороны, кВт.

Максимальная мощность, потребляемая выпрямителем ВД-201, составляет 4,9 кВт.

Время упрочнения зуба бороны 0,04 ч. Тогда расход электроэнергии составит 0,2 кВт на деталь $(0,04 \cdot 4,9)$.

Затраты на электроэнергию, потребляемую источником питания, для упрочнения одного зуба бороны составят:

$$
\mathrm{C}_{\text {ип1 }}=0,2 \cdot 6,45=1,3 \text { руб. }
$$

Расчет расхода электроэнергии на освещение ведется по формуле:

$$
\mathrm{P}_{\mathrm{O} 1}=\mathrm{P}_{\text {оу }} F_{\text {уч }} \mathrm{T}_{\text {оп }} / 1000, \mathrm{\kappa} \mathrm{B} \text {, }
$$

где $\mathrm{P}_{\text {оу }}$ - удельный расход электроэнергии на освещение, Вт $/ \mathrm{M}^{2}$ в ч; $F_{\text {уч }}$ - площадь сварочно-наплавочного участка, $\mathrm{M}^{2}$.

Средний удельный часовой расход электроэнергии составляет $20 \mathrm{BT} / \mathrm{M}^{2}$. Площадь участка равна $20 \mathrm{~m}^{2}$.

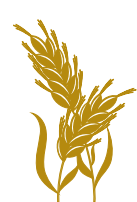


Таким образом, расход электроэнергии на наплавку одного зуба бороны будет составлять:

$$
\mathrm{P}_{\text {о1 }}=20 \cdot 20 \cdot 0,04 / 1000=0,02 \text { кВт. }
$$

Определение затрат на расходуемую электроэнергию на освещение сварочно-наплавочного участка ведется по формуле:

$$
\mathrm{C}_{\mathrm{O} 1}=\mathrm{P}_{\mathrm{O} 1} \mathrm{C}_{\mathrm{KB}} \text {, руб. }
$$

Затраты на освещение для наплавки одного зуба бороны составят:

$$
\mathrm{C}_{\mathrm{O} 1}=0,02 \cdot 6,45=0,13 \text { руб. }
$$

Затраты на электроэнергию при наплавке одного зуба бороны:

$$
\mathrm{C}_{\ni 1}=1,3+0,13=1,43 \text { руб. }
$$

Затраты ОАО «Плодопитомник» на наплавку одного зуба:

$$
\mathrm{C}_{1}=8,4+4,1+1,43+4,1=18,03 \text { руб. }
$$

Определение стоимости одного зуба бороны после наплавки выполняется по формуле:

$$
\mathrm{C}_{\mathrm{X}}=\mathrm{C}+\mathrm{C}_{\mathrm{x} 1} \text {, руб. }
$$

где C - стоимость нового зуба бороны, руб.

Стоимость одного упрочненного зуба составит:

$$
\mathrm{C}_{\mathrm{y}}=56+18,03=74,03 \text { руб. }
$$

Определение количества стандартных и наплавленных зубьев борон, требующих замены, осуществляется по формуле:

$$
\begin{gathered}
N^{3 \mathrm{cт}}=H \mathrm{~N} / \mathrm{R}_{\text {ст }}, \text { руб.; } \\
N^{3 \mathrm{y}}=H \mathrm{~N} / R_{\text {ст }} k_{И},
\end{gathered}
$$

где $H$ - средняя сезонная наработка бороны, га; $R_{\text {ст }}$ - peсурс, га на борону (15 га); $N$ - количество зубьев на бороне, шт. (20 шт.); $k_{\text {и }}$ значение среднего коэффициента износостойкости наплавленного зуба (по данным эксплуатационных исследований $\left.k_{\text {и }}=2,7\right)$.

Общая площадь боронования в ОАО «Плодопитомник» составляет 2000 га. Всего в агрегатах при бороновании применяется 108 борон в два ряда.
Таким образом, средняя наработка на одну борону в год составляет около 9 га (2000/108 = 18,5 га, при двухрядном агрегатировании 18,5/2 = 9,2 га).

Таким образом, количество зубьев, требующих замены, составит:

стандартных:

$$
N_{\mathrm{C}}^{3 \mathrm{cr}}=\frac{9 \cdot 20}{15}=12 \mathrm{w \textrm {T }} \cdot
$$

наплавленных:

$$
N_{\mathrm{c}}^{3 \mathrm{y}}=\frac{9 \cdot 20}{15 \cdot 2,7}=4 ш \mathrm{~T} .
$$

Определение экономии затрат на покупку деталей на борону осуществляется по формуле

$$
\mathrm{马}_{\mathrm{A}}=\mathrm{C} N^{3 \mathrm{CT}}-\mathrm{C}_{\mathrm{y}} N^{3 \mathrm{y}} \text { руб. }
$$

Таким образом, экономия затрат на покупку зубьев, требующих замены, в течение года на одну борону составит

$$
Э_{\mathrm{A}}=56 \cdot 12-74,03 \cdot 4=376 \text { руб. }
$$

Годовая экономия с учетом общего количества борон в ОАО «Плодопитомник» будет определяться по формуле:

$$
Э=Э_{\mathrm{A}} n, \text { руб. }
$$

где $n$ - количество борон в ООО «Плодопитомник», шт.

Тогда экономия составит:

$$
Э=376 \cdot 108=40608 \text { руб. }
$$

\begin{tabular}{|c|c|c|c|}
\hline № п/П & Наименование показателя & $\begin{array}{c}\text { Единица изме- } \\
\text { рения }\end{array}$ & Значение \\
\hline 1 & Сезонная наработка бороны & га & 9 \\
\hline 2 & Стоимость стандартных деталей & \multirow{2}{*}{ руб./шт. } & 56 \\
\hline 3 & Стоимость упрочненных деталей & & 74,03 \\
\hline 4 & Ресурс стандартных деталей & га на борону & 15 \\
\hline 5 & Средний коэффициент износостойкости упрочненных деталей & - & 2,7 \\
\hline 6 & Количество стандартных деталей, требующих замены на борону & ШТ. & 12 \\
\hline 7 & Количество упрочненных деталей, требующих замены на борону & Шт. & 4 \\
\hline 8 & Экономия затрат на покупку деталей на одну борону в год & руб. & 376 \\
\hline 9 & Общее число борон & ШТ. & 108 \\
\hline 10 & Экономия затрат на покупку деталей для всех борон в год & руб. & 40608 \\
\hline
\end{tabular}

Результаты проведения технико-экономической оценки предлагаемой наплавки зубьев сведены в таблицу.

Заключение. Годовая экономия денежных средств при обработке земель боронами с упрочненными наплавкой зубьями в условиях ОАО «Плодопитомник» по сравнению с использованием стандартных борон составляет 376 и 40608 руб. на одну и все бороны соответственно.

\section{СПИСОК ЛИТЕРАТУРЫ}

Экономические показатели упрочнения зубьев борон электродуговой наплавкой 
1. Бусарова Т.А., Колганова Н.В., Соколова И.С. Оценка экономического эффекта от внедрения НИОКР на наукоемком предприятии // Вестник НГИЭИ. Княгинино: НГИЭУ. - 2018. - № 3 (82). - С. 130-143.

2. Веселовский М.Я., Барковская В.Е. Организационно-экономические аспекты развития малого инновационного предпринимательства // Вестник НГИЭИ. Княгинино: НГИЭУ. - 2018. - № 6 (85). - С. 109-120.

3. Крупин А.Е., Зуйков Д.В. Отсеивание факторов при планировании эксперимента // Вестник НГИЭИ. 2014. - № 4 (35). - С. 62-70.

4. Крупин А.Е., Тарукин Е.М., Маслов И.М. Износостойкость покрытий при упрочнении зубьев борон электродуговой наплавкой // Вестник ВСГУТУ. 2018. - № 3 (70). - С. 48-54.

5. Полянская Н.M. Резервы повышения эффективности сельскохозяйственной продукции в условиях импортозамещения // Вестник НГИЭИ. Княгинино: НГИЭУ. - 2018. - № 1 (80). - С. 96-111.

6. Пронин В.М., Прокопенко В.А. Технико-экономическая оценка эффективности сельскохозяйственных машин и технологий по критерию часовых эксплуатационных затрат / Минсельхоз России. - М., 2008. - 165 с.
7. Синдяев Н.И. Теория планирования эксперимента и анализ статистических данных: учеб. пособие для магистров. - 2-е изд., перераб. и доп. - Серия: Магистр. - М.: Юрайт, 2014. - 495 с.

8. Шкляр В.Н. Планирование эксперимента и обработка результатов. Конспект лекций для магистров по направлению 220200 «автоматизация и управление в технических (мехатронных) системах». - Томск, 2010. -90 c.

9. https://tiu.ru.

10. http://plavitmetall.ru/elektrody/uoni-13-55texnicheskie-xarakteristiki.html.

Крупин Александр Евгеньевич, канд. техн. наук, доиент кафедры «Технический сервис», Нижегородский государственный инженерно-экономический университет. Россия.

606340, г. Княгинино, ул. Октябрьская, $22 a$.

Тел.: 89108795199.

Ключевые слова: борона; зуб; износостойкость; наплавка; обоснование; рабочий орган; иелесообразность; экономия.

\section{THE RATIONALE FOR THE HARDENING THE TEETH OF HARROWS MANUAL WELDING}

Krupin Aleksandr Evgenjevich, Candidate of Technical Sciences, Associate Professor of the chair "Technical Service", Nizhniy Novgorod engineering-economic University. Russia.

Keywords: harrow; tooth; wear resistance; surfacing; justification; working body; expediency; economy.

The article presents an algorithm to justify the feasibility of hardening the teeth of harrows by surfacing and the results of its implementation. In particular, based on existing meth- ods, it is proposed to determine the cost of materials, the wages of the worker, carried out surfacing, the cost of electricity for surfacing, as well as the overhead per one tooth harrow hardened by the proposed method. The number of deposited teeth of harrows and teeth without hardening is determined, which will require replacement upon transition to the limiting state. Based on the results obtained, cost savings were found for the purchase of teeth requiring replacement during the year on one harrow and in the whole enterprise.

удк 631.58

\section{ЦИФРОВЫЕ ТЕХНОЛОГИИ В СЕЛЬСКОМ ХОЗЯЙСТВЕ}

\section{СоЛОВьЕВ Дмитрий Александрович, Саратовский государственный аграрный университет имени Н.И. Вавилова}

ЖУРАВЛЕВА Лариса Анатольевна, Саратовский государственный аграрный университет имени Н.И. Вавилова

\section{БАХТИЕВ Ринат Нягимович, Саратовский государственный аграрный университет имени} Н.И. Вавилова

В статъе рассматриваются возможности совершенствования технологии обработки почвы, внесения удобрений, ядохимикатов и орошения путем комплексного внедрения ицфровъх технологий и интеллектуально-советующих систем управления сельскохозяйственными машинами. В Саратовском государственном аграрном университете им. Н.И. Вавилова ведутся исследования систем управления сельскохозяйственными машинами, обеспечивающими удаленный контроль работы, сбор и передачу данных о ходе выполнения технологических операций, основанных на использовании компьютерных технологий. Разрабатывается роботизированная платформа для использования навесного оборудования, выполняющего технологические операции внесения удобрений и полива на основе принципа «точного земледелия». Совершенствуется система управления роботизированного оросительного комплекса.

Введение. Обеспечение продовольственной безопасности в современном мире - одна из важнейших задач развития сельского хозяйства. Согласно прогнозам [7], производство продовольствия во всем мире должно увеличиться на
70-100 \% к 2050 г., чтобы удовлетворить потребности девятимиллиардного населения.

Борьба за повышение плодородия почв ведется разными способами и бессистемно, что заметно снижает эффективность применяемых 